\title{
Development of a concentrated oil spray programme on avocados to control insect and mite pests
}

\author{
R.E. Gaskin ${ }^{1}$ and H.A. Pak ${ }^{2}$ \\ ${ }^{1}$ Plant Protection Chemistry ${ }_{N Z}$, P O Box 6282, Rotorua 3043, New Zealand \\ ${ }^{2} 121 D$ Plummers Point Road, RD2 Tauranga 3172, New Zealand \\ Corresponding author: robyn.gaskin@ppcnz.co.nz
}

\begin{abstract}
Best practice guidelines have been developed in recent years for application of low volume, concentrated pesticide sprays to avocado orchards. Oil sprays, an important component of spray programmes on avocado orchards, have been excluded from the concentrate programme because of the risk of damage to the crop. Two unreplicated trials were undertaken on commercial orchards, one each in Northland and Bay of Plenty, from December 2012-December 2013. Each plot consisted of a single orchard block (ca 1 ha) per treatment. Dilute ( $0.5 \%$ oil) high volume sprays (up to 3000 litres/ha) were compared with concentrated ( $1.5 \%$ oil) low-volume sprays (up to 1000 litres/ha) containing a horticultural superspreader adjuvant. Monitored pest populations were comparable in both treatments throughout the year with no detrimental impacts of concentrate oil sprays on either export packout rates or storage quality of fruit after harvest. Safe use of concentrate oil sprays on avocados is practical using a horticultural superspreader adjuvant.
\end{abstract}

Keywords spray oils, dilute sprays, concentrate sprays, superspreader adjuvant, six-spotted mite, greenhouse thrips, scale insects, leaf rollers.

\section{INTRODUCTION}

Oil sprays are an important component of airblast spray programmes on New Zealand avocado orchards for control of six-spotted mite (SSM, Eotetrancyhus sexmaculatus (Riley, 1890) (Acari: Tetranychidae)), greenhouse thrips (Heliothrips haemorrhoidalis (Bouche, 1833) (Thysanoptera: Thripidae)), armoured scales (Latania scale - Hemiberlesia lataniae (Signoret, 1869)) and greedy scale (Hemiberlesia rapax (Comstock, 1881)) (Hemiptera: Diaspididae), in addition to being used as an adjuvant with other insecticides. Oils can be applied throughout flowering (September/October) provided they are not applied when bees are actively foraging, while most insecticides can only be applied pre- or post-flowering. Oil sprays also reduce the risk of pesticide residues being present on fruit after harvest and are therefore a useful alternative to other insecticide sprays, but the risk of phytotoxicity limits their use. Up to now oils have been applied as dilute high volume sprays to avoid crop damage. The recommended use rate of oils is $0.5 \%$ in dilute sprays (e.g. 3000 litres/ha). They may occasionally be used at $1 \%$ but phytotoxicity, seen as severe leaf drop, is a serious risk at this and any higher concentration, especially when applied to stressed trees.

Best practice guidelines established for avocado growers (Manktelow \& May 2009; Gaskin et al. 2008), include application of three 
times concentrate pesticide sprays to orchards in one-third of typical dilute spray volume and utilising specialised superspreader adjuvant(s). Such practice maintains or improves pest control (Gaskin et al. 2011) and the gains for growers, in spraying efficiency and orchard returns, can be substantial. However, oils are excluded from the concentrate spray programme because the risk of crop damage is perceived to be much greater when the oil concentration in the spray mix is effectively tripled. Despite this, some growers are already applying oils in concentrate sprays and confirmation of their safety is highly desired by them and other potential users of concentrate spray programmes.

A preliminary study was undertaken on a commercial Bay of Plenty (BOP) orchard in 2010-2011, applying concentrate oil sprays with a calibrated backpack sprayer to 5-year-old Hass trees (R. Gaskin, Plant Protection Chemistry ${ }_{\mathrm{NZ}}$, unpublished report). Concentrating the oil three times (1.5\% Excel), by reducing spray application volumes (from 3000 to 1000 litres/ha), caused no damage to avocado fruit or foliage when superspreader adjuvants were included in sprays applied at monthly intervals from August to January. This was followed by two trials on larger blocks of trees conducted on two commercial orchards, in Northland and Bay of Plenty, during 2013. The objective was to test the safety and efficacy of concentrate oil spray programmes, applied by growers in a commercial environment.

\section{MATERIALS AND METHODS}

The studies were conducted between December 2012-December 2013 in two commercial orchards, each containing 9-year-old Hass trees, located in Northland (Whangarei) and BOP
(Katikati). Each orchard contained two blocks of similar area (ca $1 \mathrm{ha}$ ), tree size, microclimate and soil. Each study utilised the grower's own airblast sprayer, which was professionally calibrated by Spray-Tec prior to the study commencing. The grower's individual spray programmes were followed in both studies such that pesticide choice and timing of applications were their decisions.

Identical sprays were applied to both blocks on an orchard, except that whenever oil was applied, one block (Dilute) received a dilute oil spray and the other block (Concentrate) received the same amount of oil per hectare applied in one-third of the spray volume (Table 1). All concentrate sprays included a superspreader adjuvant DuWett ${ }^{\circledR}$ (Etec Crop Solutions, Auckland, New Zealand), or if rain was forecast within 5 days of spraying, then Du-Wett was substituted with the latex-based superspreader/sticker, Bond ${ }^{\circledR}$ Xtra (Etec Crop Solutions) (Table 1) at double the recommended rate per hectare. The Best Practice recommendations for concentrate spraying of avocados include these adjuvants as essential when reducing spray application volumes (Gaskin et al. 2008). Separate spray diaries were kept for each block.

Oil spraying commenced in December 2012 on the BOP orchard, and seven oil sprays (D-CTron Plus; 843 g/litre mineral oil; Fruitfed Supplies, Te Puke, New Zealand) were applied for SSM control to December 2013; three of these were applied with Du-Wett and four with Bond Xtra. At the Northland site, oil (D-C-Tron Plus) spraying commenced in January 2013 and three sprays, all containing Du-Wett, were applied for SSM control to end April 2013. Oils were applied both as separate applications and in conjunction with other pesticides. Sprays were applied to both

Table 1 Oil spray treatments applied to orchards in Northland and Bay of Plenty (BOP)

\begin{tabular}{|c|c|c|c|c|c|c|}
\hline \multirow[b]{2}{*}{$\begin{array}{l}\text { Orchard } \\
\text { location }\end{array}$} & \multirow[b]{2}{*}{$\begin{array}{c}\text { Oil rate } \\
\text { (litres/ha) }\end{array}$} & \multicolumn{2}{|c|}{ Dilute spray } & \multicolumn{3}{|c|}{ Concentrate spray } \\
\hline & & $\begin{array}{c}\text { Volume } \\
\text { (litres/ha) }\end{array}$ & $\begin{array}{c}\text { oil conc. } \\
(\%)\end{array}$ & $\begin{array}{c}\text { Volume } \\
\text { (litres/ha) }\end{array}$ & $\begin{array}{c}\text { oil conc. } \\
(\%)\end{array}$ & $\begin{array}{l}\text { Du-Wett }{ }^{1} \\
\text { (litres/ha) }\end{array}$ \\
\hline Northland & 15 & 3000 & 0.50 & 1000 & 1.5 & 0.5 \\
\hline BOP & 8 & 2400 & 0.33 & 800 & 1.0 & 0.4 \\
\hline
\end{tabular}

${ }^{1}$ Bond Xtra used instead at double this rate when rain expected. 
orchards according to Avogreen monitoring results. Dilute and Concentrate blocks received identical pesticide treatments except that an additional application of Paramite was made to the Dilute block in Northland, and in BOP an additional Calypso application was made to the Dilute block and an Avid spray to the Concentrate block, as a result of differences in monitored pest populations. Crop monitoring using AvoGreen protocols was undertaken by Fruitfed Supplies for 12 months commencing December 2012. In BOP, the trial blocks were monitored 12 times, at approximately monthly intervals. In Northland, the blocks were monitored 20 times because SSM infestation was far higher in Northland. Monitoring recorded mites (eggs and adults), leafrollers (eggs and larvae), scale insects, thrips, mealybugs and beneficial insects. Assessment of fruit and foliage for any sign of phytotoxic damage due to Concentrate sprays was regularly monitored by the growers.

Fruit was harvested from the Northland orchard on 11 November 2013 and packed on 12 November. The BOP Concentrate block was picked and packed on 25/27 November, respectively, while the BOP Dilute block dates were 27/28 November. Each treatment block on each orchard was harvested as a separate pack run and assessed for export packout (\%), total fruit yield $(\mathrm{kg})$ and fruit size by commercial packhouses. Packout export reject analysis recorded the percentage of reject fruit because of leafroller, thrips and scale infestation, and soft fruit. Library trays (20 fruit) for each block on each orchard were collected at the time of packing. These trays were removed from cool storage $\left(4^{\circ} \mathrm{C}, 85 \% \mathrm{RH}\right)$ approximately 28 days after picking and assessed for firmness, colour and presence of fuzzy patches and peel damage. Fruit was ripened at $20^{\circ} \mathrm{C}$ until eating firmness was reached and then assessed for ripe fruit disorders (Dixon 2003).

Treatment effect on pest populations was assessed using a paired sample t-test with unequal variances, separately for each grower. The effect of treatment on harvested green and ripened fruit was assessed using a one-way analysis of variance (ANOVA) separately for each grower. Both analyses were performed using Microsoft Excel.

\section{RESULTS AND DISCUSSION}

Monitoring of the major pests found that there were no significant differences in average pest populations over the season between the Dilute and Concentrate sprays (Table 2). This was confirmed by the harvest data reject analysis (Table 3 ), which showed comparable reject rates for leafrollers and thrips for the Northland orchard, and leafrollers for the BOP orchard. The packout data for BOP indicates that thrips damage was higher in the Dilute block, despite no differences observed in the pest monitoring (Table 2). This highlights the limitations of the monitoring data as a surrogate measure of pest damage.

SSM monitoring data from Northland are shown in Figure 1. SSM infestation was high initially in the Dilute block at the start of the trial. From mid-December to early May mite numbers were similar in the two treatments. Mite numbers increased rapidly over winter

Table 2 Average pest populations (percentage of monitoring sites infested) from the AvoGreen monitoring over the growing season for two grower properties with Dilute and Concentrate oil applications. Treatment effect assessed using a paired sample t-test with unequal variances, separately for each grower (ns= not significant).

\begin{tabular}{|c|c|c|c|c|c|c|}
\hline \multirow[b]{2}{*}{ Pest } & \multicolumn{3}{|c|}{ Northland orchard } & \multicolumn{3}{|c|}{ Bay of Plenty orchard } \\
\hline & Dilute & Concentrate & T-test & Dilute & Concentrate & T-test \\
\hline SSM adult & 6.5 & 5.9 & ns & 1.6 & 2.3 & ns \\
\hline Thrips & 0 & 0 & ns & 5.6 & 4.2 & ns \\
\hline Leaf roller & 0.5 & 0.8 & ns & 1.3 & 1.0 & ns \\
\hline Mealy bug & 2.2 & 1.1 & ns & 0.6 & 1.1 & ns \\
\hline
\end{tabular}


Table 3 The percentage of fruit rejected due to leafrollers, thrips and soft fruit, and the number of reject fruit inspected at packout for each block. Data are from reject analysis of export fruit.

\begin{tabular}{lccccc}
\hline & \multicolumn{2}{c}{ Northland } & & \multicolumn{2}{c}{ BOP } \\
\cline { 2 - 3 } \cline { 5 - 6 } & Dilute & Concentrate & & Dilute & Concentrate \\
\hline Leaf roller (\%) & 10.2 & 8.2 & & 41.3 & 46.3 \\
Thrips (\%) & 0 & 0 & & 17.4 & 6.0 \\
Soft fruit (\%) & 0 & 0 & & 0.7 & 0.9 \\
No. fruit inspected & 49 & 49 & & 325 & 674 \\
\hline
\end{tabular}

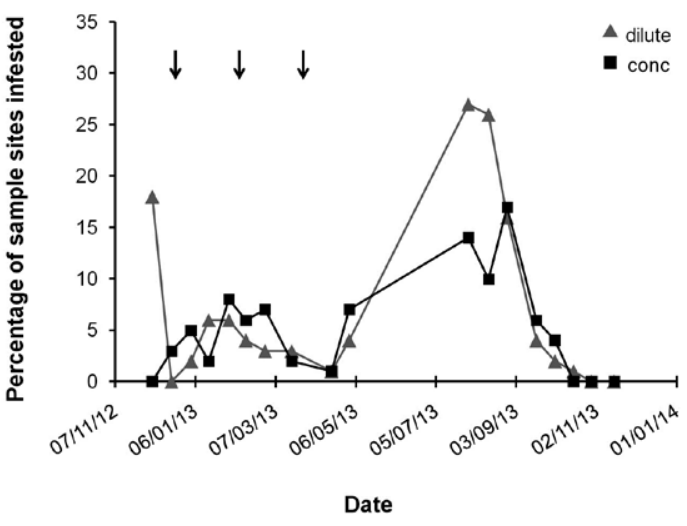

Figure 1 Six-spotted mite monitoring data for Northland. Arrows indicate timing of oil spray applications.

peaking at the end of July, especially on the dilute oil treatment block. A mite growth regulator, etoxazole (ParaMite ${ }^{\circledR}$, GroChem), was applied to both blocks at the end of July. In BOP SSM infestations were lower, with effectively none recorded except in July and August (data not presented).

Both the Northland and BOP growers confirmed that no negative effects were observed on leaf canopy density or colour, or leaf drop in the Concentrate, relative to the Dilute, treatments throughout the course of the study. Both growers were routinely applying oils as concentrate sprays with the addition of Du-Wett or Bond Xtra for several years prior to the commencement of this study and confirmed they perceived no added risk due to the treatment.

In the Northland orchard no difference in yields, export packout rates or average fruit size could be attributed to Concentrate oil applications (Table 4). Overall yield was low relative to $\mathrm{BOP}$, but this was typical for the Whangarei region in the 2013 season. The low fruit set in this region resulted in mainly single hanging fruit with low numbers of rejects. In comparison, BOP had much higher yields with consequently more touching fruit (a favoured site for leafroller and thrips) and hence, higher numbers of these pests and a lower packout rate. Packout rates and average fruit size for the two treatments were similar for BOP, but yield for the Dilute treatment was only $60 \%$ of the Concentrate treatment. This difference was confirmed as arising from factors governing fruit set on the two blocks prior to the applications of the treatments (i.e. biennial bearing) and is not a result of any treatment effects.

The comparison of export fruit reject rates due to pest pressure (leafroller and thrips) between Northland and BOP (Table 3) reflect

Table 4 Total yield (kg), export grade packout (\%) and average fruit size (count per $5.5 \mathrm{~kg}$ tray) for Dilute and Concentrate oil applications. Data are from packhouse generated reports.

\begin{tabular}{lccccc}
\hline & \multicolumn{2}{c}{ Northland } & & \multicolumn{2}{c}{ BOP } \\
\cline { 2 - 3 } \cline { 5 - 6 } & Dilute & Concentrate & & Dilute & Concentrate \\
\hline Total yield $(\mathrm{kg})$ & 1,280 & 1,242 & & 11,395 & 18,793 \\
Export packout $(\%)$ & 89.6 & 89.5 & & 70.9 & 71.7 \\
Fruit size (count) & 21.4 & 21.9 & & 24.2 & 24.2 \\
\hline
\end{tabular}


the yield data (Table 4), with higher export packouts resulting from lower pest pressure in Northland. Although SSM populations were high in Northland (Figure 1), this pest feeds on the undersurface of leaves and does not affect fruit quality. Reject rates for leafroller damage were similar for Dilute and Concentrate oil treatments in each orchard. Rejects due to soft fruit were very low for both treatments for both orchards.

The Library tray green fruit assessment (Table 5) confirmed all fruit were in a reasonable condition on removal from cool storage with no soft fruit. Northland fruit from the Concentrate oil treatment had more brown colouration than the Dilute treatment, but the severity of fuzzy patches, the key pathological disorder of green fruit, was significantly $(\mathrm{P}<0.05)$ lower. There were no significant differences between treatments for green fruit quality from the BOP trial. Peel damage was the same across both treatments indicating that the Concentrate oil had not made the fruit more susceptible to handling damage during harvest.

The ripe fruit assessments (Table 5) confirmed fruit from both trials ripened normally, taking between 3-4 days on average to reach eating ripeness on removal from cool storage, which is typical for fruit harvested during late November/ December. Fruit from the BOP Concentrate oil treatment ripened more quickly, but this is likely due to the additional fruit age, caused by the 2-day delay in harvesting the Dilute treatment block. Fruit colouration was again higher in Northland fruit from the Concentrate oil treatment. There were no significant differences between treatments in the severity of fungal rots (brown patches symptomatic of body rots on ripe fruit and stem-end rots), which were low overall, with the exception of brown patches in the Northland trial. This most likely reflects the lack of copper fungicide applications during the growing season. A key concern with concentrate oil applications was the possibility that the oil could occlude the

Table 5 Comparison of library tray data comparing the Dilute and Concentrate treatments for two orchards. Values for firmness are based on hand firmness assessments. Colour is based on a graded ripening scale $(0=$ bright green, $100=$ black). Values for fuzzy patches, peel damage, stem-ends rots, vascular browning, diffuse flesh discolouration and brown patches are average severity of the disorder as a percentage of fruit area affected.

\begin{tabular}{|c|c|c|c|c|c|c|}
\hline & \multicolumn{3}{|c|}{ Northland } & \multicolumn{3}{|c|}{ BOP } \\
\hline & Dilute & Conc. & ANOVA $^{1}$ & Dilute & Conc. & ANOVA $^{1}$ \\
\hline \multicolumn{7}{|c|}{ Green fruit assessments } \\
\hline Firmness & 0 & 0 & ns & 0 & 0 & ns \\
\hline Colour & 35.5 & 44.8 & $* *$ & 28.0 & 26.3 & ns \\
\hline Fuzzy patches & 6.0 & 1.7 & * & 3.6 & 9.0 & ns \\
\hline Peel damage & 35.7 & 39.1 & ns & 23.5 & 15.0 & ns \\
\hline \multicolumn{7}{|c|}{ Ripe fruit assessments } \\
\hline Days to ripen & 3.5 & 3.3 & ns & 3.6 & 3.1 & $* * *$ \\
\hline Firmness & 85 & 85 & ns & 85 & 85 & ns \\
\hline Colour & 66.8 & 71.5 & * & 77.0 & 70.0 & ** \\
\hline Stem-end rots & 0.1 & 0 & ns & 0.1 & 0.2 & ns \\
\hline Vascular browning & 1.0 & 0 & ns & 0 & 0.3 & ns \\
\hline Diffuse flesh & 0 & 0 & ns & 0 & 0 & ns \\
\hline Brown patches & 4.8 & 4.7 & ns & 0.9 & 1.1 & ns \\
\hline
\end{tabular}

${ }^{1}$ Values for the P-value from the ANOVA are ns $=$ not significant, ${ }^{\star} 0.025<\mathrm{P} \leq 0.05,{ }^{\star \star} 0.01<\mathrm{P} \leq 0.025$, $\star * \star \mathrm{P} \leq 0.01$ 
lenticular openings on the fruit surface, which allow for gaseous exchange. However, the key physiological disorders (vascular browning and diffuse flesh discolouration) were virtually absent in the assessed fruit, with no significant treatment differences.

\section{CONCLUSIONS}

In both the Northland and BOP orchards, concentrated $(1.5 \%$ oil $)$ low-volume sprays (up to 1000 litres/ha) containing a specialist superspreading adjuvant performed similarly to dilute $(0.5 \%$ oil) high volume sprays (up to 3000 litres/ha) applied to avocados. No negative effects were observed on leaf canopy density or colour. Monitored pest populations were comparable on both treatments throughout the year with no detrimental impacts of concentrate oil sprays on either export packout rates or storage quality of fruit after harvest. In particular, concentrate oil sprays caused no key physiological disorders in fruit. It is concluded that the use of $3 \times$ concentrate oil sprays on avocado crops is possible with the inclusion of the horticultural superspreader adjuvants, Du-Wett or Bond Xtra.

\section{ACKNOWLEDGEMENTS}

This study was funded by Etec Crop Solutions. Thanks to the two growers, Jack Crozier (Bay of Plenty) and Mark West (Northland), who willingly and enthusiastically participated in the study. Fruitfed Supplies undertook crop monitoring and Agfirst BOP analysed library trays and undertook return yield assessments, on both orchards. The Avocado Industry Council Ltd provided access to spray diaries. Darren Faire and Garry Elliott (Etec) are thanked for providing valuable assistance and advice.

\section{REFERENCES}

Dixon J 2003. New Zealand Avocado Fruit Assessment Manual. Avocado Industry Council Ltd, Tauranga, New Zealand.

Gaskin RE, Steele KD, Manktelow DWL, Pak H, Elliott GS 2011. VII World Avocado Congress, Sepember 2011, Cairns, Australia. 11 pp. http://www.worldavocadocongress2011. com/userfiles/file/Garry\%20Elliot\%2013501410.pdf (accessed 15 April 2014).

Gaskin RE, Manktelow DWL, Pak H 2008. Improving spray distribution and coverage on avocado trees in low volume, concentrate sprays. New Zealand Plant Protection 61: 147-152.

Manktelow D, May W 2009. Distance based spraying: using tree height and density to define chemical application rate requirements for NZ avocados. AvoScene, December 2009: 23-25. 